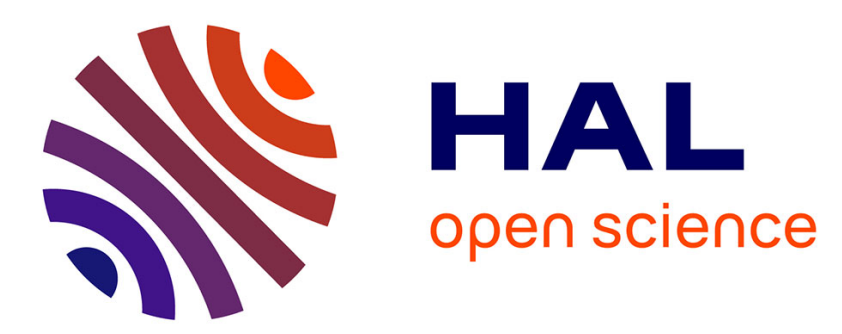

\title{
Getting Collaborative Networks Sustainable: Drivers and Barriers Within a Digital Laboratories Network
}

Valentin Kammerlohr, Heiko Duin, Jannicke Baalsrud Hauge, Nadera Sultana

\section{To cite this version:}

Valentin Kammerlohr, Heiko Duin, Jannicke Baalsrud Hauge, Nadera Sultana. Getting Collaborative Networks Sustainable: Drivers and Barriers Within a Digital Laboratories Network. 22nd Working Conference on Virtual Enterprises (PRO-VE 2021), Nov 2021, Saint-Etienne, France. pp.31-40, 10.1007/978-3-030-85969-5_3. emse-03324364

\section{HAL Id: emse-03324364 \\ https://hal-emse.ccsd.cnrs.fr/emse-03324364}

Submitted on 24 Nov 2021

HAL is a multi-disciplinary open access archive for the deposit and dissemination of scientific research documents, whether they are published or not. The documents may come from teaching and research institutions in France or abroad, or from public or private research centers.
L'archive ouverte pluridisciplinaire HAL, est destinée au dépôt et à la diffusion de documents scientifiques de niveau recherche, publiés ou non, émanant des établissements d'enseignement et de recherche français ou étrangers, des laboratoires publics ou privés. 


\title{
Getting Collaborative Networks Sustainable: Drivers and Barriers Within a Digital Laboratories Network
}

\author{
Valentin Kammerlohr ${ }^{1,2(\bowtie)}$, Heiko Duin ${ }^{3}$, Jannicke Baalsrud Hauge ${ }^{3,4}$, \\ and Nadera Sultana Tany ${ }^{5}$ \\ ${ }^{1}$ Hochschule für Technik Stuttgart, Stuttgart, Germany \\ Valentin.Kammerlohr@hft-stuttgart.de \\ ${ }^{2}$ Auburn University College of Business, Auburn, USA \\ ${ }^{3}$ BIBA - Bremer Institut Für Produktion Und Logistik GmbH, Bremen, Germany \\ ${ }^{4}$ KTH-Royal Institute of Technology, Södertälje, Sweden \\ ${ }^{5}$ University of Bremen, Bremen, Germany
}

\begin{abstract}
Rapid technology changes and the transition to digitalised production and education pose significant challenges to engineering education. Hands-on experimentation requires access to new technologies, often in a lab setting. Crossorganisational collaboration and resource sharing can reduce costs and increase utilisation. Success depends on trust, practical resource management, smooth service delivery, and performance. This paper presents an initial evaluation of a resource management approach using an online lab booking process, considering stakeholders' various roles and needs. In addition, we gathered external inputs through two surveys targeting industry and students as potential customers and interviews with professionals working in collaborative working environments to assess drivers and barriers to network success using SCOR metrics. These findings are essential inputs for lower-level design decisions, such as designing the underlying business models, the relationship between education and research for the labs, the rules of use, and how to motivate collaborators.
\end{abstract}

Keywords: Collaborative network $\bullet$ Trust $\bullet$ Sustainability $\bullet$ Digital laboratories - Shared resources $\bullet$ Adaptability

\section{Introduction}

Sharing economies have a strong traditional practice on the one hand side; on the other hand, we see several new digitalised shared economies that would not work without technological advances $[1,2]$. The concept of a sharing economy can also be applied to digital laboratories (lab). Digital labs outline a solution and describe virtual and remote labs, where personal presence in the lab is not required but accessible via the internet. This reduces entry barriers, allows worldwide access, and enables the application towards sharing economy. Advantages of virtual labs can be safety, scalability, remote access, higher utilisation, and cost-efficiency. A more detailed explanation of how labs get digitalised and the different variations like access to the resource (local/remote), nature of lab (real/virtual), or involved organisations (one/multiple) can be found in [3]. However, virtual labs cannot fully replace real/physical lab environments, as different knowledge is required and encouraged when manipulating real hardware [4]. 
One of the biggest challenges for the growth of a sharing economy is establishing trust $[2,5,6]$, including the different stakeholders' understanding of trust [5, 7-9]. In the scope of a sharing economy, the actors need to know and trust on: "(1) states (conditions) of shareable assets regarding the capacity, presence and (idle time), capability; (2) previous experience in the sharing of the same resource; (3) restrictions and compensation; (4) level of behavioural congruence of actors participating in the sharing; (5) regulatory issues and dispute resolution" [10]. Furthermore, the relevance and what is considered relevant vary in the literature, both depending on the field of application and the phase of the networked organisation. For shared lab environment, factors related to elements of virtual enterprises [7], role-based trust, interpersonal and inter-organisational trust, institutional-based trust [11], static and dynamic trust factors [9], and the elements of service relationships incl. personal trust [6, 12] apply [10]. Trust problems are gathered by Daudi [13] and are the complexity of the sharing network structure, uncertainties of the logistics processes, and behaviour of the partners.

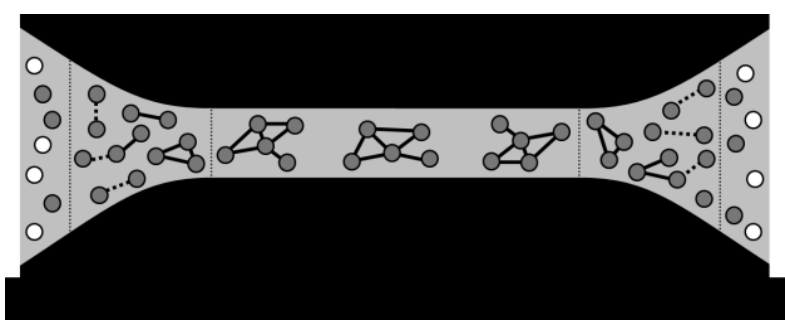

Fig. 1. From Virtual Organisations to long-term collaboration

The success of operating shared resources in a collaborative network over a longer time depends not only on the trust but also on the business considerations and the needs of all stakeholders. Fig. 1 above illustrates how a virtual organisation's setup and evolution operates over time. The stakeholders go through the phases of preparation in which the relationships between stakeholders are formed, operation in which the evolution of the virtual organisation takes place, and decomposition in which the virtual organisation dissolves. Many research projects can be seen as virtual organisations where the typical customer is the funding organisation. The common goal and vision are stated in the project proposal and work description [14]. These have a temporary character ending when the funding ends. If such collaboration continues to exist after a funding period (which would be an evolutionary step in the figure above), mutual interest and a business model fitting the different stakeholders' needs and preferences need to be developed. Each stakeholder gets an added value higher than what each organisation can achieve alone, both in the medium and long term. Based on these considerations, we have identified three research questions:

1. Do the identified metrics match people's experience having years of experience working both in collaborative research projects and establishing long-term collaborations after the project ended? For this purpose, we have interviewed experienced people, and currently, the analysis of 4 of these are included here.

2. Related to existing stakeholders in the collaboration (i.e., the virtual, temporary one)- to what extent do they feel that the developed process model fits their needs 
and requirements. For this, each stakeholder was asked to fill in a feedback template.

3. The current business model foresees that the consortium gets funding and thus, at the moment, does not need to look into the return-on-investments. However, this funding will not last for long, and a stable and solid long-term collaboration regarding shared resources needs to generate income at least matching their costs. For investigating this, two online surveys have been designed and distributed to two potential user groups: a) students b) companies that could be interested in using the educational offer for the life-long training of their employees.

The rest of the paper is structured as follows: Section 2 describes the research methodology, while section 3 outlines the current setup and the intended future structure of the network. Section 4 presents the interviews, the feedback forms, and the online surveys, while section 5 discusses the findings and the contribution to the research questions. Section 6 concludes the paper and outlines further research steps.

\section{Research Methodology}

This paper investigates factors that contribute to a successful transition from a projectbased collaboration as a virtual organisation towards a long-term partnership in a collaborative network. To address related questions, we have used a blended research method consisting of:

- Two semi-structured online surveys (open \& closed questions) to gather requirements and demands for the shared laboratory network. One online survey to understand the purpose of the students and one for understanding the industry by surveying Italian companies. The survey for students contained 25 questions, while the survey for companies included 23 questions.

- Expert Interviews were used for investigating the operationalisation factors of the cognitive trust model. We used semi-structured interviews with four pre-defined questions. The interview time varied between $45 \mathrm{~min}$ and three h. Currently, we have analysed the results of four interviews.

- A feedback survey with participants representing all stakeholder types currently involved. These have validated the process flow of future collaborative services.

\section{Collaborative Network of Shared Laboratories}

The public-funded cross-institutional research project DigiLab4U intends to provide a digitalised lab environment that enables a learning marketplace for digital lab facilities [3]. The goal is to develop an integrated, hybrid learning and research environment consisting of a variety of lab technologies for a digital offering that can be used by any student, from undergraduate to graduate, anywhere. The research consortium consists of four German and one Italian academic institution working on digitalising and sharing their education, training and research labs. The DigiLab4U learning marketplace consists of digital labs from various providers on the one hand and users accessing the 
labs on the other. The cooperation between universities, research institutions, and industry makes it possible to bundle the providers' resources so that users, such as learners and researchers, have access to a greater variety of digital courses based on different labs. A critical step in the project is to increase the number of participants on both sides (providers and buyers) to increase the platform's value, the so-called network effect $[15,16]$. An important starting point for sustainable development prospects of the marketplace is to strengthen the trust of suppliers, users, and marketplace providers $[16,17]$.

To ensure sustainability after research funding ends, a multi-sided platform is to be used as a business and collaboration model for sharing these labs. The multi-sided platform is a hub or intermediary for exchanging value between interested parties and providers from two or more markets [16]. In the case of a digital lab network, the interested party includes students, professors/lecturers/teachers, researchers, industry companies, and research institutes (collectively referred to as buyers). The suppliers are universities, research institutes, and industry companies (or vendors, collectively referred to as suppliers), as shown in Fig. 2. The marketplace aims to bring together the supplier of the labs with the buyer [16]. The challenges of a multi-sided platform, according to Henseling et al. [17], are: (1) building user trust, (2) further developing marketplace offerings, and (3) attracting new user groups.

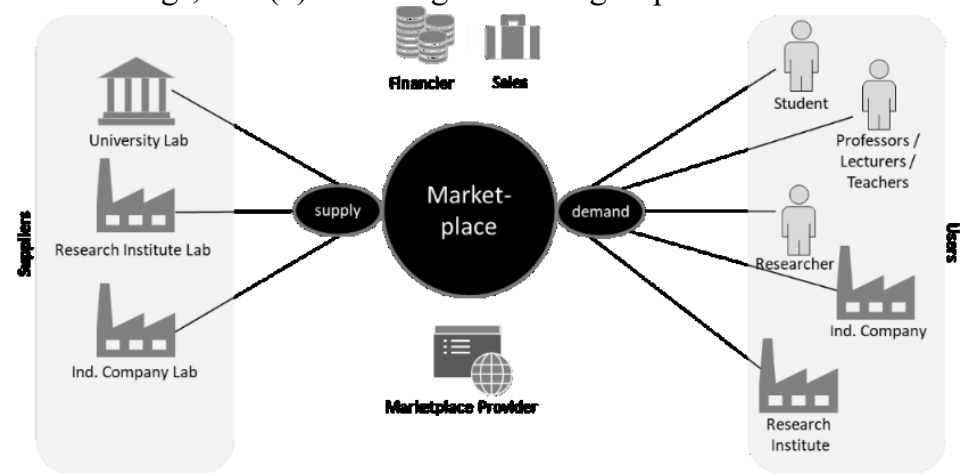

Fig. 2: Stakeholders of the Digital Lab Marketplace

As the temporary collaborative lab network is to be transformed into a sustainable long-term collaboration, the stakeholders' goals might change from collaboratively ensure the fulfilment of the funder's requirement towards goals that fits into the longterm company strategy. In some cases, it will hardly be any changes in the goals. In some cases, partners will have such different purposes that they will leave the collaboration. However, the corresponding business model will change since the revenue streams will change as the stakeholder Funding Institution has to be replaced with another type of customer. To address how different factors influence the transition of the collaboration and the need to identify new revenue streams, the next section will present the expert interviews and surveys results. 


\section{Evaluation Results}

For evaluation purposes, four streams have been followed. Two online surveys in February through April 2021 have been conducted concerning the service's customer side, including students and industrial companies. Another survey addressed the processes for resource booking among the current members of the virtual labs' network. Finally, semi-structured interviews with external experts have been conducted to verify the metrics and key performance indicators for success.

\subsection{Understanding Potential Customers: Student \& Company Survey}

93 students participated in the survey ( $43 \%$ female). The majority of students were already aware of digital labs before our survey, and $12 \%$ used digital labs in their academic curriculum/practice. The experienced students are under the explicit conditions of adding value to the learning experience. Participants who had no prior experience expect digital labs to provide valuable content $(70 \%)$, ease of use $(67 \%)$, affordability (48\%), otherwise inaccessible materials and equipment (59\%), and customer support (39\%). And what would keep them from using the digital labs are technology (65\%) (effectiveness of the service), organisation (55\%) (management of the service), and safety or security (26\%). The feedback on the willingness to pay and thus the financial maintenance of digital labs is controversial. The majority expect universities to pay (54\%), followed by government (35\%), students $(6 \%)$, and the rest from a mixture. Finally, students expect a clear added value from the marketplace compared to regular classes at the university. Twenty-one entrepreneurs and practitioners (18 managers or heads of technical departments) from the Northern Italy area participated in the survey to better understand industrial customers' interest in the supply and demand side of the multi-sided platform. The results show that industry customers have a strong interest in using digital labs as customers; examples given were solutions for mechanics, electrics, and electronics. None of the participants has yet used a digital lab. Nevertheless, $67 \%$ say they see digital labs as applicable for continuously improving business practices or the portfolio of offerings to customers. Limitations are found in the cost-benefit ratio, unique value proposition, data security, and the risk of losing intellectual property. Especially for small and medium-sized companies, digital labs represent an economical and flexible alternative to direct experimentation possibilities. Another possible motivator mentioned the current travel restrictions, with digital labs enabling remote testing and experimentation. Regarding the financial sustainability of digital labs and marketplaces, $67 \%$ of respondents believe they can be considered fee-based service offerings.

\subsection{Cognitive Model of Trust, Expert Interviews}

Four expert interviews have been carried out and analysed to assess the operationalisation of the cognitive trust model. A semi-structured interview approach was used, where the questions were defined in advance. The main supporting factors for successful collaboration are around open communication. Interviewees said that 
knowing each other from previous projects helps and being open-minded, talking the same language (in terms of professional jargon), transparency, and visibility. Monetary and resource-based aspects do complicate collaboration. Delays caused by not following the defined procedures and processes and not communicating them, and/or following an own hidden agenda are critical for the success of the collaboration. Another inhibiting factor is territorial behaviour. The common goals and a clear vision need to be in place. A common understanding of how the results are exploited after the project-based collaboration ends needs to be defined before the long-term collaboration starts. The critical success factors for the long-term sustainability of collaboration are ROI (Return on Investment), market opportunities, reliability, responsiveness, balanced relationships, and resource provision. Concerning the SCOR Level 1 Metrics, all interviewees agree that Perfect Order Fulfilment is most important in both respects, internal (within the collaboration) and external (towards the customer of the collaboration). Other important metrics include Order Fulfilment Cycle Time, Upside Supply Chain Flexibility, Upside Supply Chain Adaptability, and Downside Supply Chain Adaptability. Cost and related financial metrics are considered not particularly important.

\subsection{Stakeholders' Feedback on Booking Process Model}

The evaluation of the resource usage process is based on the (TO-BE) digital lab booking process model developed in an earlier phase of the project. Five different groups of potential users, depending on their role in the partner organisation lab facilities, have been identified and surveyed: Professors, Lab Managers, Lab Operators, Researchers, and Students (as Learners). The evaluation process consisted of presenting a process model involving their role followed by a simple questionnaire. A total of 32 responses have been collected, of which three are from professors, two from lab managers, six from lab operators, seven from researchers, and 14 from students.

Out of 32 responses, 29 respondents agreed that their roles are reflected in the proposed process model, two disagreed, and another did not respond. One participant argues that the "Student" role and the "Researcher" role do not differ in the process. Unless additional features are included or excluded from one of these roles, combining them into one "Lab User" role is more meaningful. The other participant wants to have access to things that are more aligned with their research interest. 15 participants want to see possible changes in the system. 16 participants found the process model adequate, and one did not respond. The critical feedback of the third question includes: Users want to have an option to do a test of the lab setup or a chance to apply for an examination of the lab setup before the teaching start. We see that $88 \%$ of the participants from different action roles find that their role is positively reflected in the process model. $81 \%$ of the participants think that the processes necessary to their specific function are addressed in the process model. And finally, 50\% of the participants do not want to change the process model presented to them; $47 \%$ want to have changed in the system from the other half. This shows that the process model can cater to the role-specific needs of users even though there is room for improvement. 


\section{Discussion}

For sustainable participation in a digital lab marketplace by industrial companies, a cost-benefit ratio, a unique selling proposition of the solutions, data security, and intellectual property protection is essential. From the perspective of these, fee-based service offerings for digital labs are conceivable as financial sustainability, relying on market regulation. In contrast, students expect valuable content, ease of use, affordability, otherwise inaccessible materials and equipment, and customer support. A problematic issue is the willingness to pay; traditionally, education in Europe is free. Students accept that the effort of a digital lab has to be paid for, but there is a significant dispute whether the state should pay this, the university or the student himself. The cost-benefit discussion is also reflected in the trust model: the cognitive model of trust shows that trust-related factors dominate collaboration success. This includes a common understanding of objectives and processes and appropriate and collaborative behaviour among partners. Therefore, it is not astonishing that Perfect Order Fulfilment is the central metric to measure a collaboration's success combined with metrics addressing flexibility and adaptability. A majority of the participants from the evaluation survey of the booking process provide a positive response to the presented process model. Those participants think that these processes are essential and that their specific role is addressed in the model. Half of the participants do not want to change the process model presented to them; the other half requested changes to the system. This shows that there is room for improvement.

Returning to the research questions, we can conclude that the identified metrics match people's experience having years of experience working both in collaborative research projects and establishing long-term collaborations. Existing stakeholders in the collaboration feel that the developed process model fits their needs and requirements despite identifying improvement needs. Future users are willing to pay, but there is no common sense of who should do it.

\section{Conclusion and Outlook}

This paper has investigated different factors that influence the transformation from a temporarily (virtual) organisation towards a long-term networked collaboration as well as the possibility to replace one type of customer (funding organisation) with a different kind (students and companies willing to use shared labs). The expert interviews show that long-term collaboration depends very much on trust factors like reliability, order fulfilment, and response time. Variations are depending on whether the organisations have common previous experience and not. The two surveys conclude that these respondents assess the access to shared laboratory resources as positive, even if quite a few have experience in using remote and virtual labs. In the next step, we will need to improve the booking process and investigate if this collaboration can be seen as a product-service system and then explore what services will contribute to a sustainable collaboration that can act smart in a dynamic field. 
Acknowledgements. This work has been funded by the German Federal Ministry of Education and Research (BMBF) through the project DigiLab4U (No. 16DHB2112 and 16DHB2113).

\section{References}

1. Belk, R.: Why Not Share Rather Than Own? The ANNALS of the American Academy of Political and Social Science 611, 126-140 (2007)

2. Behrendt, S., Henseling, C., Scholl, G. (eds.): Digitale Kultur des Teilens. Mit Sharing nachhaltiger Wirtschaften. Springer Fachmedien, Wiesbaden (2019)

3. Kammerlohr, V., Pfeiffer, A., Uckelmann, D.: Digital Laboratories for Educating the IoTGeneration. Heatmap for Digital Lab Competences. In: 17th International Conference on Remote Engineering and Virtual Instrumentation, pp. 10-27. Springer-Verlag, Berlin, Heidelberg (2020)

4. Nedic, Z., Machotka, J., Nafalski, A.: Remote laboratories versus virtual and real laboratories. In: Frontiers in Education, T3E_1-6. IEEE, Westminster, CO, USA (2003)

5. Goudin, P. (ed.): The Cost of Non-Europe in the Sharing Economy. Economic, Social and Legal Challenges and Opportunities. European Parliamentary Research Service, Brussels (2016)

6. Johnson, D.S., Grayson, K.: Sources and Dimensions of Trust in Service Relationships. Handbook of Service Relationship, 357-370 (2000)

7. Fladnitzer, M., Grabner-Kräuter, S.: Vertrauen als Erfolgsfaktor virtueller Unternehmen. Grundlagen, Rahmenbedingungen und Maßnahmen zur Vertrauensbildung. Deutscher Universitäts-Verlag, Wiesbaden (2006)

8. Mayer, R.C., Davis, J.H., Schoorman, F.D.: An Integrative Model of Organizational Trust. The Academy of Management Review 20, 709 (1995)

9. Daudi, M.: Trust in Sharing Resources in Logistics Collaboration. Bremen (2018)

10. Baalsrud Hauge, J., Kammerlohr, V., Göbl, B., Duin, H.: Influence of Trust Factors on Shared Laboratory Resources in a Distributed Environment. In: PRO-VE 2019, pp. 624-634 (2019)

11. Bachmann, R., Inkpen, A.C.: Understanding Institutional-based Trust Building Processes in Inter-organisational Relationships. Organisation Studies 32, 281-301 (2011)

12. Johnson, D., Grayson, K.: Cognitive and affective trust in service relationships. Journal of Business Research 58, 500-507 (2005)

13. Daudi, M., Hauge, J.B., Thoben, K.-D.: Behavioral factors influencing partner trust in logistics collaboration: a review. Logist. Res. 9 (2016)

14. Seifert, M.: Collaboration formation in virtual organisations by applying prospective performance measurement. Aachen (2009)

15. Eisenmann, T.R., Parker, G., van Alstyne, M.W.: Strategies for Two-Sided Markets. Harvard Business Review Vol. October, 2006, 1-12 (2006)

16. Abdelkafi, N., Raasch, C., Roth, A., Srinivasan, R.: Multi-sided platforms. Elec. Markets 29, 553-559 (2019)

17. Henseling, C., Hobelsberger, C., Flick, C., Behrendt, S.: Nachhaltige Entwicklungsperspektiven für Geschäftsmodelle des Peer-to-Peer Sharing. PeerSharing Arbeitsbericht 6. Berlin (2018) 